\title{
Are two-dimensional images sufficient to assess the atherosclerotic plaque vulnerability: a viscoelastic and anisotropic finite element model
}

\author{
Mehrdad Zareh', Guy Fradet ${ }^{1,3}$, Gholamreza Naser ${ }^{1}$ and Hadi Mohammadi ${ }^{1,2,3^{*}}$
}

*Correspondence: hadi.mohammadi@ubc.ca

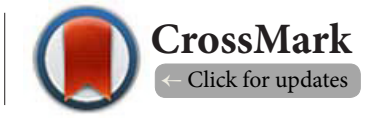

${ }^{1}$ The Heart Valve Performance Laboratory, School of Engineering, Faculty of Applied Science, University of British Columbia, Kelowna, BC, Canada.

${ }^{2}$ Biomedical Engineering Graduate Program, Faculty of Applied Science, University of British Columbia, Vancouver, BC, Canada. ${ }^{3}$ Department of Surgery, Faculty of Medicine, University of British Columbia, Vancouver, BC, Canada.

\begin{abstract}
The correlation between plaque morphology as well as composition and plaque vulnerability has been the motivation for many recent studies. In a generic point of view, instability of atherosclerotic plaques is known to be the result of a thin fibrous cap and a large and highly compliant necrotic core area. There have been numerous two-dimensional (2D) and three-dimensional (3D) computational models mostly based on the finite element method (FEM) to assess the plaque vulnerability. It is well-known that $2 \mathrm{D}$ models are not reliable as they do not provide a consistent assessment on the vulnerability of plaques and are highly erroneous. 3D models offer a more effective evaluation but creating 3D models to be further assessed by computational means such as the finite element method is time-consuming. However, $2 \mathrm{D}$ models are easier to develop and are less time-consuming to assess. In this study, we propose a novel computational platform by which the plaque vulnerability is assessed using only $2 \mathrm{D}$ plaque models. We develop idealistic $2 \mathrm{D}$ models and their corresponding idealistic 3D models. The idealistic $3 \mathrm{D}$ models resemble the worst- and best-case scenarios for each $2 \mathrm{D}$ model. Using these $3 \mathrm{D}$ idealistic models, a standard error (SE) is estimated and then added to the peak stress values calculated earlier using $2 \mathrm{D}$ models. These SEs are also used to assess the probability of plaque stability. In this platform, the effect of viscoelasticity and anisotropy of the plaque composition is taken into consideration and the transmural pressure considered is similar to that of physiological conditions (dynamic pressure). The current study may suggest a more realistic insight to the prediction of atherosclerotic plaques rupture using $2 \mathrm{D}$ images.
\end{abstract}

Keywords: Finite element method, atherosclerotic plaque, large deformation theory, computational mechanics, numerical modeling

\section{Introduction}

Although plenty of studies have been performed on the detection and therapy of instable plaques, thrombus mediated ischemic cardiovascular disease still remains the leading cause of death in developed countries [1]. The rupture of unstable atherosclerotic plaque in coronary artery regularly leads to a significant number of ischemic cardiovascular events. Conventional procedures for the prediction of rupture based on imaging of the plaque morphology and composition $[2,3]$ still provides rather inaccurate and insufficient predictors of risk [4]. The challenge for imaging methods is that prediction of the coronary plaque rupture requires not only an accurate quantification of fibrous cap thickness [5] and necrotic core morphology [6], but also a precise knowledge of the mechanical properties of the arterial wall and plaque components at any given stage of the atherosclerotic progression [7-10].

Several reports indicated that such vulnerable plaques can be detected clinically by various techniques, including Intravascular Ultrasound (IVUS) [11,12], Optical Coherence Tomography (OCT) [13,14] Computed Tomography (CT) [15] 
Mohammadi et al. Cardiovascular System 2015,

and Magnetic Resonance Imaging (MRI) [16]. Both IVUS and OCT are used to make measurements for lesion length and lumen size, but OCT is shown to be more accurate. With intravascular imaging, OCT offers clear, photographic quality images, as opposed to grainy, lower-resolution IVUS images. Also, it is known that OCT has a resolution 10 times greater than IVUS (OCT being $10 \mu \mathrm{m}$ vs. IVUS, $100 \mu \mathrm{m}$ ) [13]. Moreover, OCT can only penetrate about 2-3 $\mathrm{mm}$ into the vessel wall, where as IVUS's penetration is 4-8 $\mathrm{mm}$. If a vessel has significantly remodeled due to plaque burden, the outline of the true lumen disappears on the OCT image and the vessel outer boundary on the IVUS images.

Finite element methods (FEM) have been extensively used as a strong tool to assess the effects of mechanical factors on instability of plaque rupture [10,17-21]. Depending on the assumption made, all of the models provided are accurate to some extent. This is because there are some major issues associated with the applied models such as: (1) the constitutive material models applied are either isotropic linear, isotropic nonlinear, or anisotropic, (2) viscous properties of atherosclerotic plaque is either overlooked or somewhat oversimplified, and (3) mostly the modeling is implemented for steady-state conditions. The main aims of this study are to develop a novel computational platform which improves the estimation of mechanical stresses applying on the fibrous cap under actual physiological loading conditions. In this study, the fibrosis is assumed to be viscoelastic and the transmural pressure is considered to be dynamic. The solver used in this study is ANSYS, R15.0, a commercial FEM code.

\section{Methods}

This study has two phases: phase l: working on idealistic models and phase II: working on real data or data obtained from patients.

\section{Phase I}

(1) 3 idealistic 2D models are developed to comprehensively define all types of plaque morphologies. As the 3D structure of these 2D models is unknown, for each idealistic 2D model, (2) 2 idealistic 3D models are developed. These 3D models are designed to provide the worst and best case scenarios for stress distribution if the 2D model were hypothetically to be considered 3D. (3) The 2D models are solved for stress analysis. (4) The 3D models are used to define lower and upper limits of the stress values obtained earlier. These limits are implemented to evaluate the plaque stability for the 2D model.

\section{Phase II}

(1) The 2D models are obtained from patients are solved for stress analysis. (2) The similar idealistic 2D model to the real 2D model is chosen. The idealistic model is chosen based on the geometry of the plaques where the fibrous cap is minimal, i.e., the most critical region. (3) The lower and upper limits obtained by the idealistic 3D models are implemented for the real model and then the probability of plaque stability is evaluated. Each stage is described below in more detail.

\section{Idealistic 2D models}

Using a comprehensive range of clinical data, a variety of authentic morphologies for plaque composition was carefully investigated. The objective of this investigation was to define principal and idealistic morphology to represent the geometry of all types of necrotic cores, fibro-athermatous caps, and arterial remodelling indexes $[16,17]$. Four representative IVUS images were carefully chosen based on the geometry of the thin fibrous cap which was then categorized to: (1) Nodal (Figure 1A), linear (Figures 1B and 1C), and curve-linear (Figure 1D) [14]. This classification was the foundation for the generation of 3 idealistic 2D models shown in Figure $1 \mathrm{E}$ (nodal), Figure 1F (linear) and Figure 1G (curve-linear). Any other types of 2D geometries of plaque can be created by one or a combination of two of these idealistic models.

\section{Idealistic 3D models}

In this section, each of the idealistic 2D models is considered separately, and then for each model, 2 further idealistic 3D models are developed such that the cross section of the plaque in the 3D models are identical. These 2 idealistic 3D models resemble the worst and best case scenarios for stress distribution, if the 2D model were hypothetically to be considered $3 \mathrm{D}$. The stress distribution values obtained from the 2D model are between the lower and upper limits obtained from the idealistic 3D models. Using these lower and upper limits, a standard error (SE) is defined and added to the results obtained from $2 \mathrm{D}$ models. Figures $2 \mathrm{~A}-3 \mathrm{D}$, Figures $2 \mathrm{~B}-2 \mathrm{E}$ and Figures $2 \mathrm{C}-2 \mathrm{~F}$ are the idealistic 3D modes regarding Figures $1 \mathrm{E}-1 \mathrm{G}$, respectively.

\section{Actual 2D imaging data obtained from real patients} In this section, 4 images (2D models) obtained from patients diagnosed with atherosclerosis are considered the subject of the study. These images are developed by two well-established imaging techniques, IVUS and OCT. Given that the IVUS technique provides images deep in the vessel wall but with less resolution compared to the OCT technique which provides a higher resolution but with less penetration, a co-registered image of these two techniques may provide a realistic geometry of the plaque composition including the fibrous cap area, the necrotic core area, and calcific nodules (if present).

\section{Constitutive model and boundary conditions}

A cylindrical coordinate is defined in which $z$ denotes the axial direction of the artery and $r$ and $\theta$ indicate the radial and circumferential directions, respectively, of the cross section of a typical plaque (Figure 1). Given that the fibrous cap is considered anisotropic, it is assumed that mechanical properties of fibrosis are identical in the axial ( $\mathrm{z}$ ) and radial (r) directions but different in the circumferential $(\theta)$ direction (much stronger) (Table 1) [23]. Er is the modulus of elasticity 

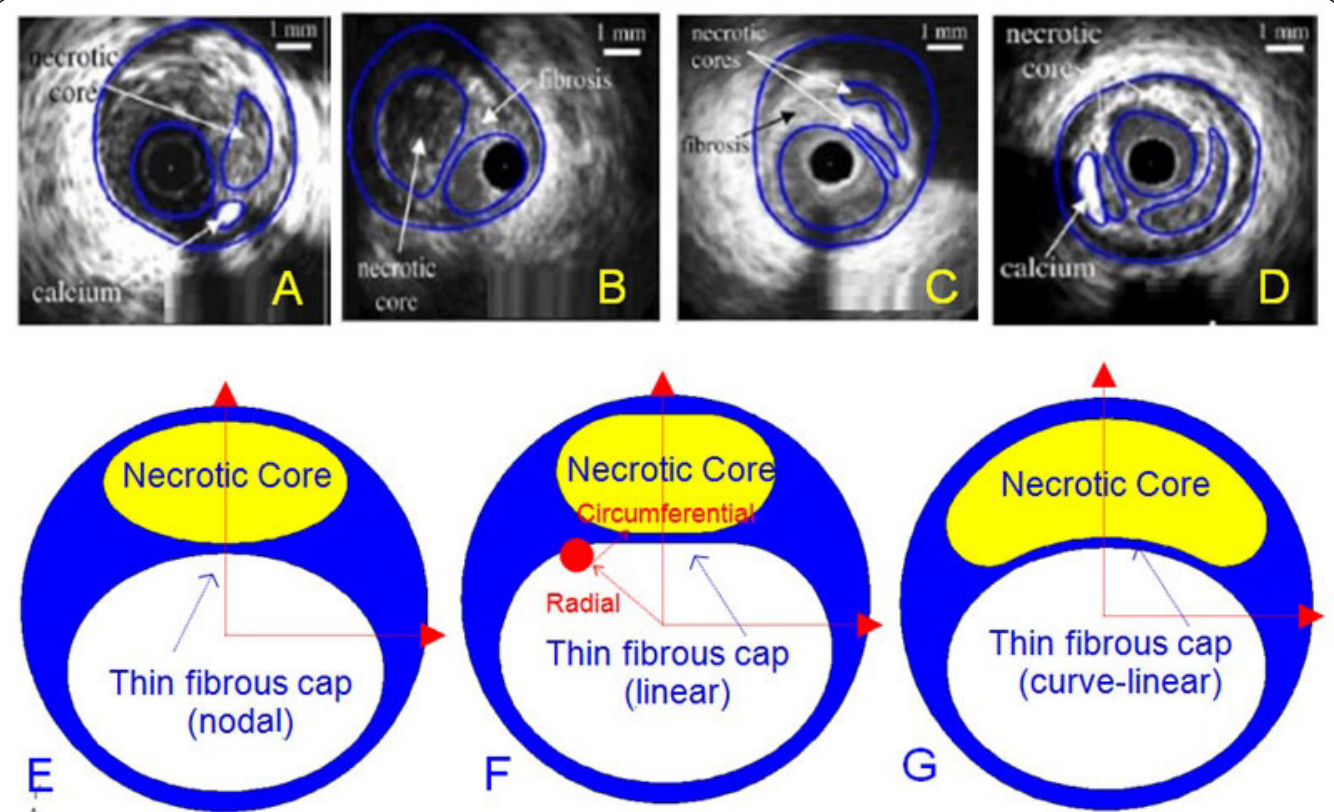

Figure 1. The chosen IVUS images which are the representative of all types of plaque morphologies. This classification is based on the geometry of the fibrous cap which is considered to be: nodal (A), linear (B,C), and curve-linear (D), and the corresponding idealistic models are defined as: $\mathbf{E}$ (nodal), F (linear) and $\mathbf{G}$ (curve linear) [22].

A

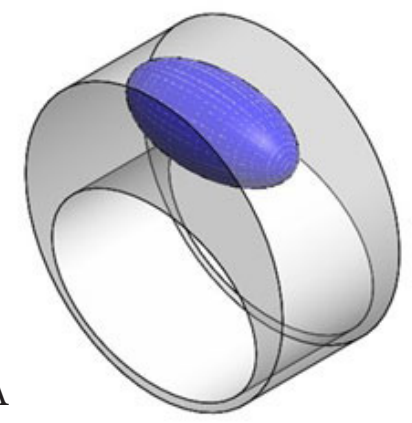

B

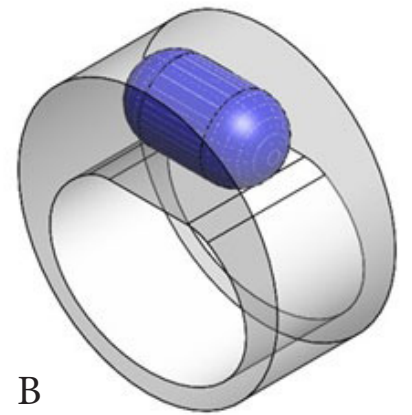

$\mathrm{E}$

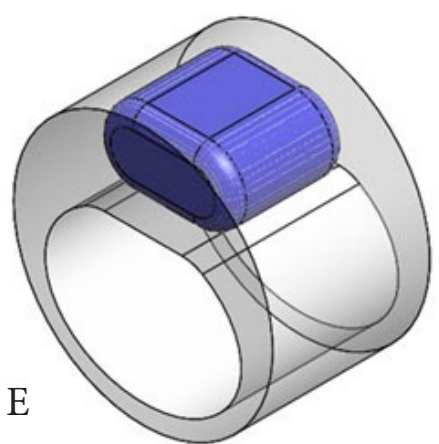

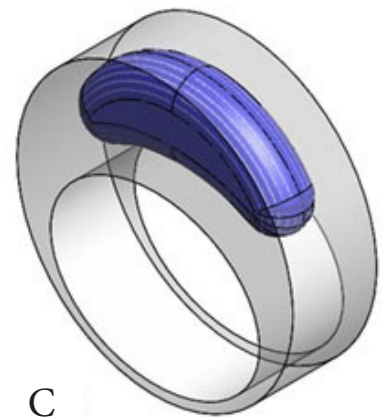

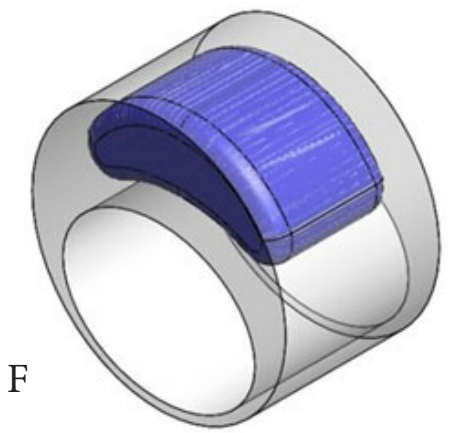

Figure 2. The idealistic 3D models developed in this study. (A-C) are considered as sphere-like models which provide the lowest value of stress in the critical zone where the cap thickness is minimal, and (D-F) provide the highest value of stress in the critical zone where the fibrous cap thickness is minimal. $(\mathbf{A}, \mathbf{D})$ are the idealistic 3D models for Figure 1E; (B,E) are the idealistic 3D models for Figure 1F; and $(\mathbf{C}, \mathbf{F})$ are the idealistic 3D models for Figure 1G. 
Mohammadi et al. Cardiovascular System 2015,

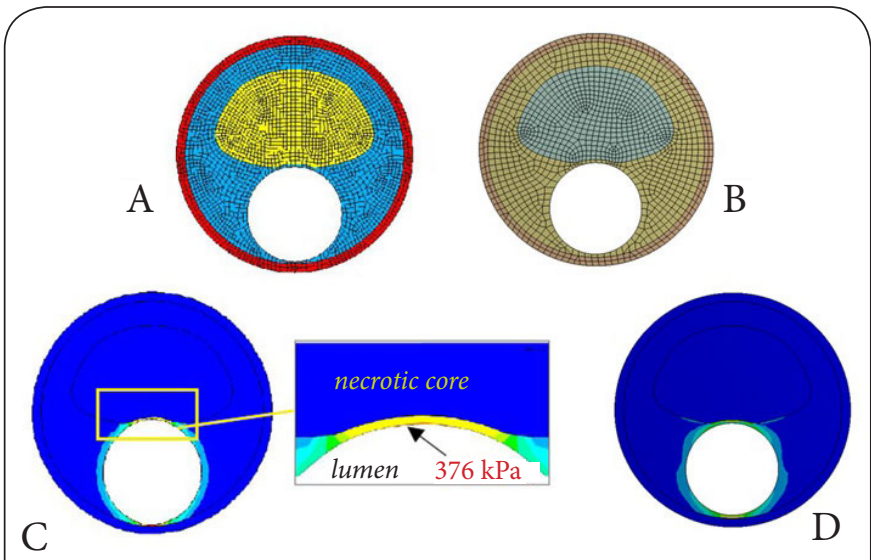

Figure 3. The validation study: (A) The mesh model by Ohayon et al., (B) The mesh model in the current study, (C) The stress distribution and the peak cap stress (PCS) obtained by Ohayon et al., [23], and (D) The stress distribution and the peak cap stress obtained in the current study. For the current model, the PCS is $378 \mathrm{kPa}$ which is $2 \mathrm{kPa}$ larger than the computed PCS in that study. This small discrepancy may be because of the differences in the mesh models.

Table 1. Mechanical properties of fibrosis [15].

\begin{tabular}{llllll}
\hline & $\mathrm{E}_{\mathrm{r}}(\mathrm{kPa})=\mathrm{E}_{\mathrm{z}}(\mathrm{kPa})$ & $\mathrm{E}_{\theta}$ & $\mathrm{V}_{\mathrm{r} \theta}$ & $\mathrm{V}_{\mathrm{rz}}=\mathrm{V}_{\theta \mathrm{z}}$ & $\mathrm{G}_{\mathrm{rz}}=\mathrm{G}_{\mathrm{r} \theta}=\mathrm{G}_{\theta \mathrm{z}}(\mathrm{kPa})$ \\
\hline Fibrosis & 100 & 1000 & 0.01 & 0.27 & 500 \\
\hline
\end{tabular}

in the radial direction, $\mathrm{Ez}$ is the modulus of elasticity in the axial direction, $\mathrm{E} \theta$ is the modulus of elasticity in the circum ferencial direction, $v_{\mathrm{r} \theta^{\prime}}, \mathrm{v}_{\mathrm{rz}}$ and $\mathrm{v}_{\theta z}$ are the Poisson's ratios.

Necrotic core or lipid pool was assumed to be isotropic with elastic modulus of $1 \mathrm{kPa}$ [18] and the Poisson's ratio of 0.49 (in compressibility) [23]. In order to define viscoelastic behavior for fibrosis, a time Prony series with its known constants was implemented (Table 2) [24]. This time Prony series has five spring-damper elements i.e;

$$
g_{R}(t)=1-\sum_{i=1}^{5} g_{i}^{-p}\left(1-e^{\left(-t / \tau_{i}\right)}\right)
$$

where relaxation times spanning five decades $(\tau 1=0.001 \mathrm{~s}$, $\tau 2=0.01 \mathrm{~s}, \tau 3=0.1 \mathrm{~s}, \tau 4=1.0 \mathrm{~s}$, and $\tau 5=10.0 \mathrm{~s}$ ) were selected. These numerical values were chosen in order to define completely the time scales of the dynamic studies. The relaxation times, $\mathrm{i}$, where $\mathrm{i}=1, \ldots, 5$, are associated with the damping coefficient $\eta$ and spring constant $E$ in each Maxwell element which is defined as $\mathrm{ti}=\eta \mathrm{i} / \mathrm{Ei}$ where $\mathrm{i}=1, \ldots, 5$. The CAD models of these three plaque morphologies were created in Solid Works 2014, and then these models were converted to ANSYS design files through ANSYS Design Module 2015. Material properties and suitable boundary conditions (fixed all around) were assigned to the models. In this study, the transmural pressure was assumed to be dynamic following the physiological conditions (Table 3) [25]. For comparison
Table 2. Elements of time prony series [24].

\begin{tabular}{lll}
\hline Index (i) & Relative module (i) & Relaxation time \\
\hline 1 & 0.1595 & 0.001 \\
2 & 0.1177 & 0.01 \\
3 & 0.0623 & 0.1 \\
4 & 0.1612 & 1 \\
5 & 0.2101 & 10 \\
\hline
\end{tabular}

between 2D and 3D models, von-Mises stress distribution (with assumption of plane strain state for $2 \mathrm{D}$ models) at $\mathrm{t}=4.2$ $s$ has been considered.

Preliminary results show that the maximum stress occurs at $\mathrm{t}=0.2 \mathrm{~s}$ but since heart beats almost 100,000 times a day, the maximum value at $\mathrm{t}=0.2 \mathrm{~s}$ seems to be numerical artifact, thus, $t=4.2 \mathrm{~s}$ (cycle 4 ) is considered for the peak stress values in which the peak dynamic stress remained unchanged (more detail is provided in the result section). For FE computation, models were meshed by ANSYS Mechanical 2015. As the stress map in the fibrous cap area is important, the mesh density in this area was selected to be high. The solver implemented in this study was Mechanical APDL 2015 running on an Intel ${ }^{\circledR}$ Core $^{\text {TM }} 2$ Due T6670 @ 2.2GHz and 2.00 GB of RAM.

\section{Results and discussion Validation}

In order to validate our proposed computational platform, one of the results in the study by Ohayon et al., [23] was reproduced and resolved. In this model, the peak cap stress (PCS) ofthe model with the same morphology, mechanical properties, blood pressure, etc., was calculated and compared. Results indicate that the PCS obtained by our solver $(378 \mathrm{kPa})$ and that of Ohayon et al., (376 kPa) shows $2 \mathrm{kPa}$ discrepancy(less than $1 \%$ error) (Figure 3 ). This small discrepancy could be because of small differences between the two mesh models.

\section{Mesh independency study}

Mesh independency of our results is of particular significance in this study which is done by performing further computation for each plaque models with higher mesh density. The mesh size is decreased until the point where by increasing the mesh density the results are not improved. The result of mesh independency study is outlined in Table 4.

\section{Case study I-effect of viscoelasticity of fibrous cap}

The idealistic model shown in Figure $1 \mathrm{E}$ is considered. The fibrous cap thickness was set to $95 \mu \mathrm{m}$ (unlike $70 \mu \mathrm{m}$ [22]), the diameter of artery is assumed to be $3.3 \mathrm{~mm}$, and the lumen area was considered elliptic with diameters of $250 \mu \mathrm{m} \times 200$ $\mu m$, representing a typical plaque.

In Figure 4, the PCS values for 2D models (Figure 1E) are shown at different times. As observed, the maximum PCS occurs at $\mathrm{t}=0.2 \mathrm{~s}$ and then this value decreases by time due to the viscoelastic behavior of fibrosis. The PCS values in the 
Mohammadi et al. Cardiovascular System 2015,

http://www.hoajonline.com/journals/pdf/2052-4358-3-3.pdf

doi: $10.7243 / 2052-4358-3-3$

Table 3. Tabular data for dynamic pressure.

\begin{tabular}{lllllllllllllll}
\hline Time $(\mathrm{s})$ & $\mathbf{0}$ & $\mathbf{0 . 2}$ & $\mathbf{0 . 8}$ & $\mathbf{1 . 2}$ & $\mathbf{1 . 8}$ & $\mathbf{2 . 2}$ & $\mathbf{2 . 8}$ & $\mathbf{3 . 2}$ & $\mathbf{3 . 8}$ & $\mathbf{4 . 2}$ & $\mathbf{4 . 8}$ & $\mathbf{5 . 2}$ & $\mathbf{5 . 8}$ & $\mathbf{6 . 2}$ \\
\hline Pressure $(\mathrm{kPa})$ & 12 & 18.7 & 10.7 & 18.7 & 10.7 & 18.7 & 10.7 & 18.7 & 10.7 & 18.7 & 10.7 & 18.7 & 10.7 & 18.7 \\
\hline
\end{tabular}

Table 4. Mesh independency study, the PCS for each model along with the number of elements used are shown in row $A$ and $B$. In row $B$, models were meshed with more elements in comparison with models in row A. Results show an acceptable range for discrepancy of PCS in each plaque model; thus, the mesh models employed in row $A$ are sufficiently precise to be used for our computational approach. PCS at $\mathrm{t}=0.2 \mathrm{~s}$ has been considered for this comparison. ${ }^{\star} \mathrm{S}$ denotes the sphere-like models and ${ }^{\star} \mathrm{C}$ the cylinderlike models.

\begin{tabular}{ll|lll|llll|lll}
\hline \multirow{2}{*}{ Models } & \multicolumn{3}{c|}{ 1E } & \multicolumn{3}{c|}{ 1F } & \multicolumn{3}{c}{ 1G } \\
\cline { 3 - 11 } & & 2D & 3D S $^{*}$ & 3D C & 2D & 3D S & 3D C & 2D & 3D S & 3D C \\
\hline \multirow{2}{*}{ A } & PCS kPa & 393 & 116 & 485 & 352 & 207 & 453 & 254 & 169 & 413 \\
& & Elements & 3411 & 112150 & 114605 & 4090 & 102222 & 108182 & 2949 & 32600 & 129493 \\
\hline \multirow{2}{*}{$\mathrm{B}$} & PCS kPa & 391 & 117 & 491 & 348 & 205 & 444 & 250 & 170 & 411 \\
& Elements & 6135 & 189184 & 187733 & 5216 & 160376 & 186908 & 6186 & 71096 & 203917 \\
\hline & Comparison \% & 0.5 & 0.8 & 1.2 & 1.1 & 1 & 2 & 1.6 & 0.6 & 0.5 \\
\hline
\end{tabular}

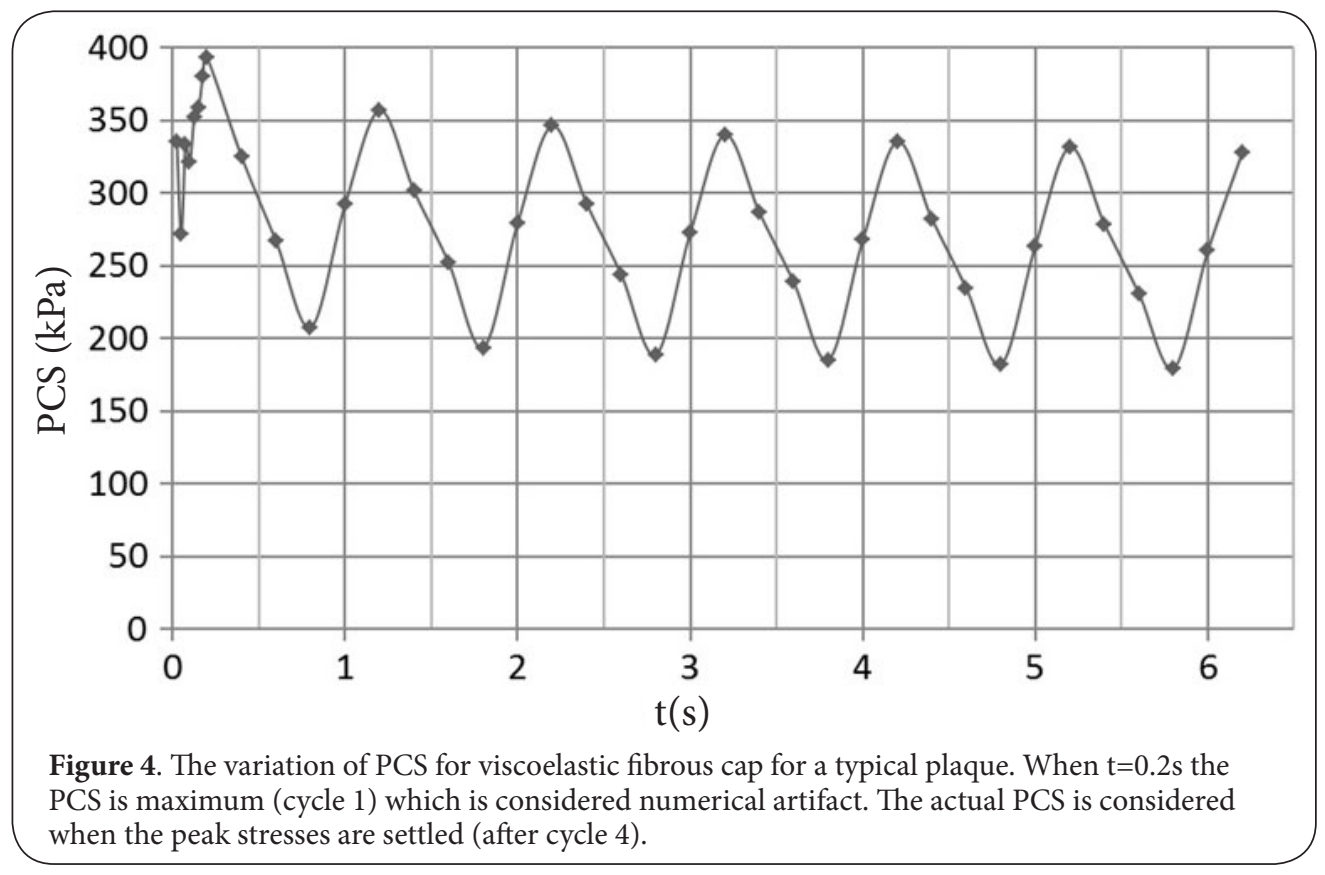

other cycles which occur at $\mathrm{t}=1.2,2.2$ and $3.2 \mathrm{~s}$, are approximately 357,346 and $340 \mathrm{kPa}$, respectively. After cycle 4, the PCS almost remains unchanged. If the simulation is run for only one cycle the PCS obtained is $393 \mathrm{kPa}$ but the plaque experiences 100,000 cycles a day such that the maximum PCS should be considered its value after cycle 4 which drops by $15 \%$ to the value of 336 at $\mathrm{t}=4.2 \mathrm{~s} \mathrm{kPa}$.

Case study II-the assessment of the PCS in the idealistic 2D models

The idealistic 2D models represented in Figures $1 \mathrm{E}-\mathbf{1 G}$ are solved for the value of PCS in the fibrous cap area (Figure 5). Results indicate that the maximum PCS (336 kPa) occurs in model $1 \mathrm{E}$ in which the fibrous cap geometry is focal. It follows with the model with a linear fibrous cap area (Figure 1F) in which the PCS is estimated to be $299 \mathrm{kPa}$ (11\% decrease) and then the curve-linear fibrous cap geometry (Figure 1G) with the PCS being $216 \mathrm{kPa}$ (36\% decrease).

The area with the maximum PCS in all models are located in the vicinity of the NC and not the lumen, which is consistent with previous studies [22]. Also, numerical values for the PCS are consistent with those obtained by Mohammadi et al., 
Mohammadi et al. Cardiovascular System 2015,

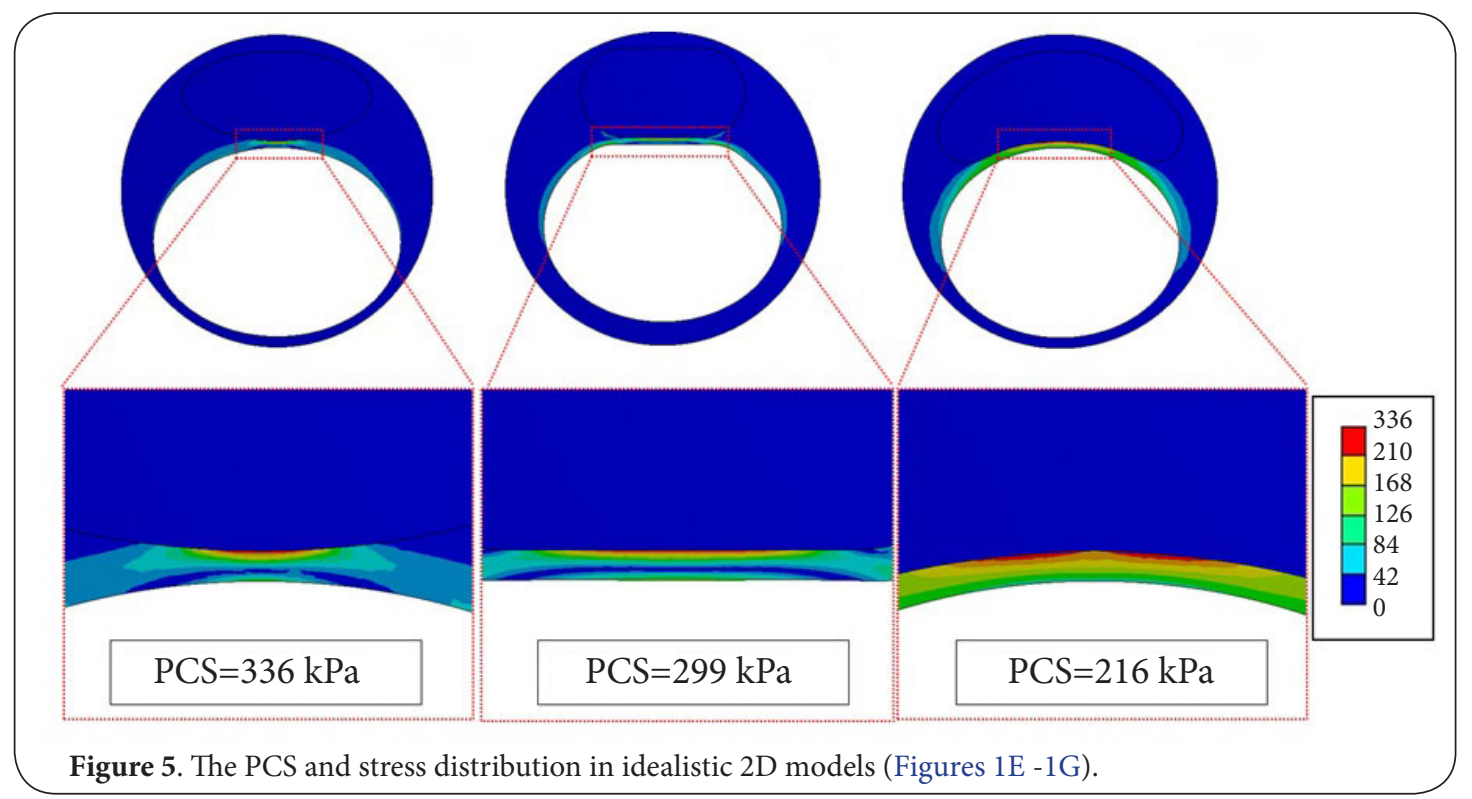

[22] with a discrepancy of $10 \%$ which is because the thinner fibrous cap considered in these models $(70 \mu \mathrm{m})$.

\section{Case study III-the assessment of the PCS in the idealistic} 3D models

In this study, two idealistic 3D models (Figure 2) are developed for each idealistic 2D model (Figures 1E-1G). Both these 3D models have the same geometry in the cross sectional area to that of the 2D model. The objective for emerging these models is that although they share the same cross sectional area of the 2D models, they are designed to yield the minimum and maximum PCS in the fibrous cap area. The stress distribution in the plaque model for these 6idealistic 3D models is shown in Figure 6.

The range of the PCS for the 3D models corresponding to Figure $1 \mathrm{E}$ is $99 \mathrm{kPa}$ to $412 \mathrm{kPa}$, whereas the PCS in the $2 \mathrm{D}$ model is $336 \mathrm{kPa}$. Since the range of $300 \mathrm{kPa}-99 \mathrm{kPa}=201 \mathrm{kPa}$ (lower limit) is greater than the range of $412 \mathrm{kPa}-300 \mathrm{kPa}=112$ $\mathrm{kPa}$ (upper limit), the 2D plaque is more likely stable. The range of $\mathrm{PCS}$ for the $3 \mathrm{D}$ models corresponding to Figure $1 \mathrm{~F}$ is $176 \mathrm{kPa}$ to $385 \mathrm{kPa}$, whereas the PCS in the 2D model is $299 \mathrm{kPa}$. Since the range of $300 \mathrm{kPa}-176 \mathrm{kPa}=124 \mathrm{kPa}$ (lower limit) is greater than the range of $385 \mathrm{kPa}-300 \mathrm{kPa}=85 \mathrm{kPa}$ (upper limit), the 2D plaque is more likely stable. The range of PCS for the 3D models corresponding to Figure $1 \mathrm{G}$ is 144 $\mathrm{kPa}$ to $351 \mathrm{kPa}$, whereas the PCS in the 2D model is $216 \mathrm{kPa}$. Since the range of $300 \mathrm{kPa}-144 \mathrm{kPa}=156 \mathrm{kPa}$ (lower limit) is significantly greater than the range of $351 \mathrm{kPa}-300 \mathrm{kPa}=51$ $\mathrm{kPa}$ (upper limit), the $2 \mathrm{D}$ plaque is likely stable. Results are outlined in Table 5, in which the discrepancy of the lower and higher limits of PCSs is compared with that of obtained from 2D models. The traditional way of evaluation of the vulnerability of plaques which is based on $2 \mathrm{D}$ models, easily
Table 5. Comparison of 2D models results with 3D models,

\begin{tabular}{|c|c|c|c|c|}
\hline \multicolumn{5}{|c|}{$\mathrm{PCS}$ in $2 \mathrm{D}$} \\
\hline & $2 \mathrm{D}$ & Sphere-like & Cylinder-like & \\
\hline \multirow[t]{2}{*}{ Model E } & $336 \mathrm{kPa}$ & $99 \mathrm{kPa}$ & $412 \mathrm{kPa}$ & $\begin{array}{l}\text { Peak cap stress } \\
(\mathrm{kPa})\end{array}$ \\
\hline & & $-70 \%$ & $23 \%$ & $\begin{array}{l}\text { Comparison with } \\
2 \mathrm{D} \text { model }^{\star}(\%)\end{array}$ \\
\hline \multirow[t]{2}{*}{ Model F } & $299 \mathrm{kPa}$ & $176 \mathrm{kPa}$ & $385 \mathrm{kPa}$ & $\begin{array}{l}\text { Peak cap stress } \\
(\mathrm{kPa})\end{array}$ \\
\hline & & $-41 \%$ & $28 \%$ & $\begin{array}{l}\text { Comparison with } \\
\text { 2D model (\%) }\end{array}$ \\
\hline \multirow[t]{2}{*}{ Model G } & $216 \mathrm{kPa}$ & $144 \mathrm{kPa}$ & $351 \mathrm{kPa}$ & $\begin{array}{l}\text { Peak cap stress } \\
(\mathrm{kPa})\end{array}$ \\
\hline & & $-33 \%$ & $63 \%$ & $\begin{array}{l}\text { Comparison with } \\
\text { 2D model (\%) }\end{array}$ \\
\hline
\end{tabular}

recommend of stability of plaques shown in Figures $1 \mathrm{~F}$ and $1 \mathrm{G}$ and instability of plaque shown in Figure $1 \mathrm{E}$.

Figure 7 shows the range of safe value $(\mathrm{PCS}<300 \mathrm{kPa})$ for PCS (green bar) and range of PCS (yellow bar) obtained using viscoelastic material model for all models. In order to assess the risk of plaque rupture, the length of the yellow bar in and out of the green zone is implemented such that:

Probability of stability of plaque $=\frac{300-\text { lower limit }}{\text { upper limit }- \text { lower limit }} \times 100$

Case study IV-effect of viscoelastic fibrosis on the PCS In this step, all nine 3D and 2D models are solved for PCS using elastic and viscoelastic material models listed in Tables $\mathbf{1}$ and $\mathbf{2}$, respectively. Results outlined in Table 6 show that in all models the PCS obtained using elastic material model is higher than 


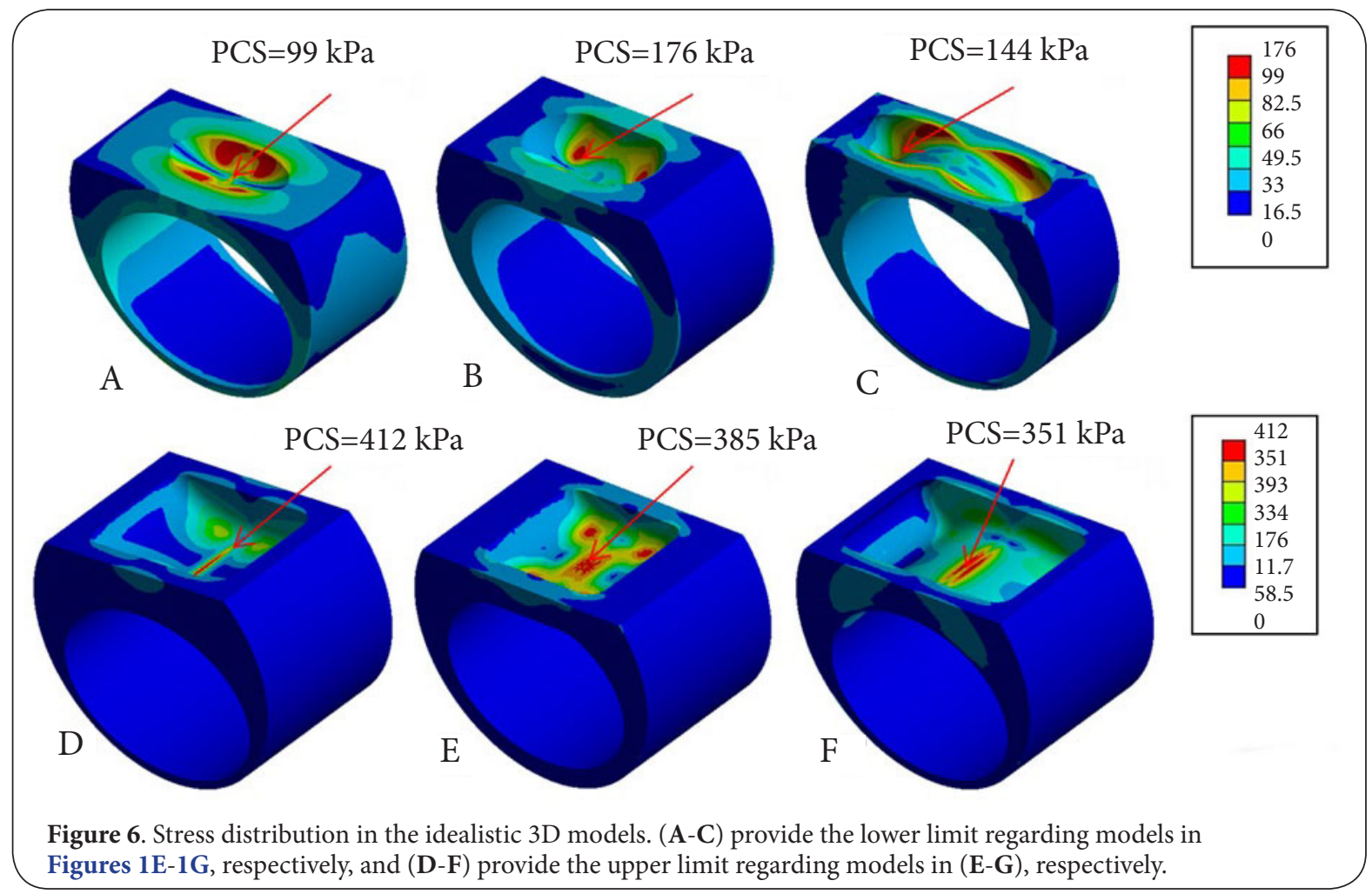

Table 6. Results of PCS computation in models with elastic and viscoelastic material. As it can be seen in the table, PCS in models with elastic material is higher than PCS in models with Viscoelastic material. PCS at $\mathrm{t}=4.2 \mathrm{~s}$ has been considered for this comparison.

${ }^{\star} \mathrm{S}$ for sphere-like models and $\mathrm{C}$ for cylinder-like models.

\begin{tabular}{l|llllllllll}
\hline \multirow{2}{*}{ Models } & \multicolumn{3}{c}{ 1E } & \multicolumn{4}{c}{ 1F } & \multicolumn{1}{c}{ 1G } \\
\cline { 2 - 10 } & 2D & 3D S $^{*}$ & 3D C & 2D & 3D S & 3D C & 2D & 3D S & 3D C \\
\hline Viscoelastic $(\mathrm{kPa})$ & 336 & 99 & 412 & 299 & 176 & 385 & 216 & 144 & 351 \\
Elastic kPa & 494 & 161 & 535 & 436 & 341 & 805 & 307 & 203 & 523 \\
Difference \% & $\sim 32$ & $\sim 38$ & $\sim 23$ & $\sim 31$ & $\sim 48$ & $\sim 52$ & $\sim 30$ & $\sim 29$ & $\sim 33$ \\
\hline
\end{tabular}

that of obtained using viscoelastic material model. For all 2D models this discrepancy is between $30-32 \%$, whereas for $3 \mathrm{D}$ models this discrepancy falls within the range of $23-52 \%$.

\section{Case study V-2D data obtained from patients}

In this section, 2D geometries of the atherosclerotic plaque obtained from 4patients were developed using the combination of OCT and IVUS techniques (co-registered image) as shown in Figures 8A-8D. In these 2D models, a clear geometry of the fibrous cap and the necrotic core is available. These 2D models are solved using the proposed computational platform for the PCS.

\section{Application on data obtained from patients}

Figure 8A1 shows the stress distribution in the entire tissue of the model shown in Figure 8A. In this model, the cap thick- ness is measured to be $0.118 \mathrm{~mm}$ and the PCS is estimated to be $355 \mathrm{kPa}$. By comparing this 2D model and the idealistic 2D models developed earlier, it is seen that this plaque has morphology similar to model 1G (Figure 1G) in general, and in particular has a similar morphology to model 1E (Figure 1E) where the cap thickness is minimal $(0.118 \mathrm{~mm})$. In order to choose similar idealistic models to an intended actual data obtained from patients, the area in which the cap thickness is minimal is considered. Following the idealistic models and their corresponding 3D models, the probable range for the PCS for such geometry is $106 \mathrm{kPa}$ to $437 \mathrm{kPa}$ and the probability of the plaque stability is calculated to be $\frac{306-106}{437-106}=59 \%$.

The conventional assessment applied for this plaque suggests that the plaque will definitely fail, but our proposed computational platform suggests that since the 3D structure 
Mohammadi et al. Cardiovascular System 2015,

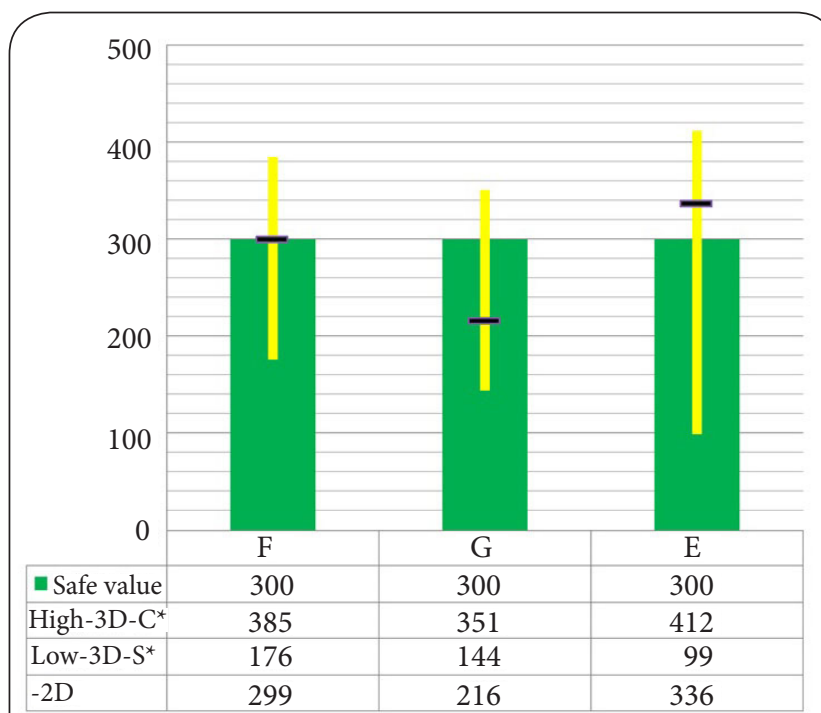

Figure 7. The range of safe value for PCS (green bar) and the total range of PCS (yellow bar). Comparison between the length of yellow bar outside and inside of green bar provides practical information about probability of rupture in a plaque. In all of these models, plaque is more likely to be stable since the probability of stability is greater than that of instability. of the plaque is not known, there is a $59 \%$ chance that the plaque may stay stable.

Figure 8B1 shows the stress distribution in the entire tissue regarding the model shown in Figure $\mathbf{8 B}$. In this model, the cap thickness is measured to be $0.067 \mathrm{~mm}$ and the PCS is estimated to be $493 \mathrm{kPa}$. Comparing this $2 \mathrm{D}$ model and the idealistic 2D models developed earlier, this plaque has morphology similar to model $1 \mathrm{~F}$ (Figure 1F). Following the idealistic models and their corresponding 3D models, the probable range for the PCS for such geometry is 0.6 PCS-1.28 PCS which is $296 \mathrm{kPa}-631 \mathrm{kPa}$, and the probability of the plaque stability is calculated to be $\frac{300-296}{631-296}=1 \%$.

The conventional assessment applied for this plaque suggests that the plaque will definitely fail, and our proposed computational platform reinforces this regardless what the $3 \mathrm{D}$ structure of the plaque might be.

Figure $\mathbf{8 C} 1$ shows the stress distribution in the entire tissue for the model shown in Figure $\mathbf{8 C}$. In this model, the cap thickness is measured to be $0.141 \mathrm{~mm}$ and the PCS is estimated to be $270 \mathrm{kPa}$. After comparing this $2 \mathrm{D}$ model and the idealistic 2D models developed earlier, this plaque has morphology similar to model 1E (Figure 1E). Following the

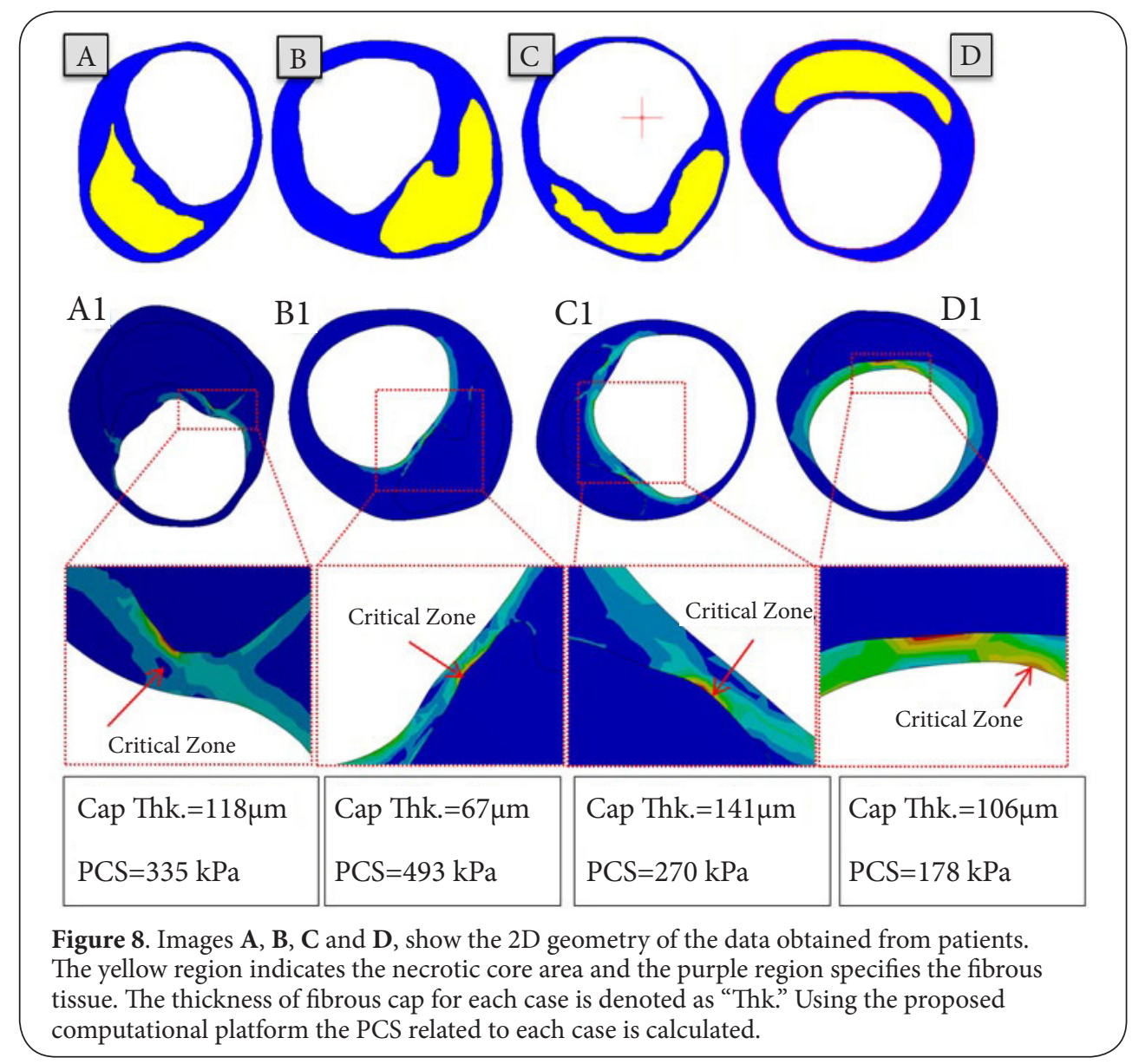


Table 7. The platform by which the $\mathrm{PCS}_{2 \mathrm{D}}$ is used for plaque stability risk assessment. The lower and upper limits are calculated using idealistic 3D models explained earlier.

\begin{tabular}{lllc}
\hline Idealistic 2D model & Lower limit & Upper limit & Probability of the plaque stability \\
\hline Figure 1E & $0.3 \times \mathrm{PCS}_{2 \mathrm{D}}$ & $1.23 \times \mathrm{PCS}_{2 \mathrm{D}}$ & $300-$ Lower limit \\
Figure 1F & $0.59 \times \mathrm{PCS}_{2 \mathrm{D}}$ & $1.28 \times \mathrm{PCS}_{2 \mathrm{D}}$ & Upper Limit - Lower Limit \\
Figure 1G & $0.67 \times \mathrm{PCS}_{2 \mathrm{D}}$ & $1.63 \times \mathrm{PCS}_{2 \mathrm{D}}$ & \\
\hline
\end{tabular}

idealistic models and their corresponding 3D models, the probable range for the PCS for such geometry is $81.1 \mathrm{kPa}$ to $332 \mathrm{kPa}$ and the probability of the plaque stability is calculated to be $\frac{300-81}{332-81}=87 \%$. The conventional assessment suggests that the plaque is most likely unstable, but our proposed computational platform suggests that since the 3D structure of the plaque is not known to us, there is a chance of $13 \%$ that the plaque may fail.

Figure 8D1 shows the stress distribution in the entire tissue regarding the model shown in Figure $\mathbf{8 D}$. In this model, the cap thickness is measured to be $0.106 \mathrm{~mm}$ and the PCS is estimated to be $178 \mathrm{kPa}$. When comparing this $2 \mathrm{D}$ model and the idealistic 2D models developed earlier, it is seen that this plaque has morphology similar to model 1G (Figure 1G). Following the idealistic models and their corresponding 3D models, the probable range for the PCS for such geometry is $119 \mathrm{kPa}$ to $290 \mathrm{kPa}$ and the probability of the plaque stability is calculated to be $\frac{300-81}{332-81}>0 \%$. The conventional assessment applied for this plaque suggests that the plaque is definitely stable and our proposed computational platform proves the stability of this plaque.

\section{Conclusion}

In this study, a novel computational platform was developed by which the vulnerability risk of an atherosclerotic plaque is evaluated by using only 2D models. We developed idealistic 2D models and corresponding 3D models (two 3D models for each) which provide the worst and best case scenarios for each 2D model. This is because the 3D structure of the plaque is not known to us, so defining the worse and best case scenarios may be helpful. The PCS is assessed in the 2D model first (denoted as $\mathrm{PCS}_{2 \mathrm{D}}$ ) and then the idealistic 3D models provide its corresponding lower and upper limits. This lower and higher limits are considered here as the standard errors (SE). Using the obtained SE, the probability of the plaque stability is assessed. In a real application and for a given $2 \mathrm{D}$ model obtained from patients, (1) The similar idealistic 2D model to the 2D model obtained from patients is found, (2) The lower and upper limits (SE) corresponding to the idealistic $2 \mathrm{D}$ model is assigned, (3) the 2D model is solved for its $\mathrm{PCS}_{2 \mathrm{D}^{\prime}}$ (4) the assigned SE is added to the calculated PCS ${ }_{2 D^{\prime}}$ and (5) the risk of plaque rupture is evaluated. For the idealistic models developed in this study, the lower and upper limits are defined as outlined in Table 7.

The computational platform seems to be useful. For example, in model shown in Figure 8B, the cap thickness is measured to be $0.067 \mathrm{~mm}$ and the PCS is estimated to be $493 \mathrm{kPa}$. Conventional evaluation models would suggest that this plaque is unstable, which is completely consistent with our results $(99 \%$, unstable). For the plaque composition, a suitable viscoelastic and anisotropic material model was considered and the transmural pressure was defined to be similar to that of physiological condition (dynamic condition). Results strongly suggest that the viscoelastic properties of the plaque composition are of particular importance for the assessment of the PCS. If elastic material model is implemented instead, for 2D models it may contribute to up to $32 \%$ error and for 3D models this error may be as high as $52 \%$. Even when viscoelastic material model is used, the difference between the PCSs obtained in the first and the fourth cycles (when PCS is settled) is almost $15 \%$.

\section{Limitations}

It should be noted that without information such as spatial resolution along all three directions of IVUS/OCT or other images, it is not possible to estimate how accurate the plaque models are. These parameters are available in the Digital Imaging and Communications in Medicine(DICOM) headers of images.

In order to improve the current work, more data analysis is required. More data obtained from patients would be helpful to be analyzed. Developing more realistic 2D and 3D models and comparing them with results obtained from 3D imaging data obtained from patients could help more strengthen the computational platform developed in this study.

\section{List of abbreviations}

IVUS: Intravascular Ultrasound

DICOM: Digital Imaging and Communications in Medicine

OCT: Optical Coherence Tomography

PCS: Peak cap stress

FEM: Finite element method

$\mathrm{CT}$ : Computed tomography

\section{Competing interests}

The authors declare that they have no competing interests. 
Mohammadi et al. Cardiovascular System 2015,

http://www.hoajonline.com/journals/pdf/2052-4358-3-3.pdf

doi: $10.7243 / 2052-4358-3-3$

Authors' contributions

\begin{tabular}{|l|c|c|c|c|}
\hline Authors' contributions & MZ & GF & GN & HM \\
\hline Research concept and design & -- & $\checkmark$ & -- & $\checkmark$ \\
\hline Collection and/or assembly of data & $\checkmark$ & $\checkmark$ & $\checkmark$ & $\checkmark$ \\
\hline Data analysis and interpretation & $\checkmark$ & $\checkmark$ & $\checkmark$ & $\checkmark$ \\
\hline Writing the article & $\checkmark$ & -- & -- & $\checkmark$ \\
\hline Critical revision of the article & -- & $\checkmark$ & $\checkmark$ & $\checkmark$ \\
\hline Final approval of article & $\checkmark$ & $\checkmark$ & $\checkmark$ & $\checkmark$ \\
\hline Statistical analysis & $\checkmark$ & $\checkmark$ & $\checkmark$ & $\checkmark$ \\
\hline
\end{tabular}

Acknowledgement

The authors acknowledge NSERC/DG and the University of British Columbia for financially supporting this work.

Publication history

Senior Editor: Juan Jose Badimon, Mount Sinai School of Medicine, USA.

Received: 12-Apr-2015 Final Revised: 24-Jun-2015

Accepted: 30-Jun-2015 Published: 10-Jul-2015

\section{References}

1. Fuster V, Moreno PR, Fayad ZA, Corti R and Badimon JJ. Atherothrombosis and high-risk plaque: part I: evolving concepts. J Am Coll Cardiol. 2005; 46:937-54. | Article | PubMed

2. Briley-Saebo KC, Mulder WJ, Mani V, Hyafil F, Amirbekian V, Aguinaldo $J G$, Fisher EA and Fayad ZA. Magnetic resonance imaging of vulnerable atherosclerotic plaques: current imaging strategies and molecular imaging probes. J Magn Reson Imaging. 2007; 26:460-79. | Article | PubMed

3. Loree HM, Kamm RD, Stringfellow RG and Lee RT. Effects of fibrous cap thickness on peak circumferential stress in model atherosclerotic vessels. Circ Res. 1992; 71:850-8. | Article | PubMed

4. Le Floc'h S, Ohayon J, Tracqui P, Finet G, Gharib AM, Maurice RL, Cloutier $\mathrm{G}$ and Pettigrew RI. Vulnerable atherosclerotic plaque elasticity reconstruction based on a segmentation-driven optimization procedure using strain measurements: theoretical framework. IEEE Trans Med Imaging. 2009; 28:1126-37. | Article | PubMed

5. Virmani R, Kolodgie FD, Burke AP, Farb A and Schwartz SM. Lessons from sudden coronary death: a comprehensive morphological classification scheme for atherosclerotic lesions. Arterioscler Thromb Vasc Biol. 2000; 20:1262-75. | Article | PubMed

6. Farb A, Burke AP, Tang AL, Liang TY, Mannan P, Smialek J and Virmani R. Coronary plaque erosion without rupture into a lipid core. A frequent cause of coronary thrombosis in sudden coronary death. Circulation. 1996; 93:1354-63. | Article | PubMed

7. Cheng GC, Loree HM, Kamm RD, Fishbein MC and Lee RT. Distribution of circumferential stress in ruptured and stable atherosclerotic lesions. A structural analysis with histopathological correlation. Circulation. 1993; 87:1179-87. | Article | PubMed

8. Finet G, Ohayon J and Rioufol G. Biomechanical interaction between cap thickness, lipid core composition and blood pressure in vulnerable coronary plaque: impact on stability or instability. Coron Artery Dis. 2004; 15:13-20. | Article | PubMed

9. Lee DD, Rigonan K and Dequattro V. Increased blood pressure and neural tone in the silent ischemia of hypertension: disparate effects of immediate release nifedipine. J Am Coll Cardiol. 1993; 22:1438-45. | Article | PubMed
10. Ohayon J, Teppaz P, Finet G and Rioufol G. In-vivo prediction of human coronary plaque rupture location using intravascular ultrasound and the finite element method. Coron Artery Dis. 2001; 12:655-63. | Article I PubMed

11. Carlier SG and Tanaka K. Studying coronary plaque regression with IVUS: a critical review of recent studies. J Interv Cardiol. 2006; 19:11-5. | Article | PubMed

12. Rioufol G, Finet G, Ginon I, Andre-Fouet X, Rossi R, Vialle E, Desjoyaux E, Convert G, Huret JF and Tabib A. Multiple atherosclerotic plaque rupture in acute coronary syndrome: a three-vessel intravascular ultrasound study. Circulation. 2002; 106:804-8. | Article | PubMed

13. Jang IK, Bouma BE, Kang DH, Park SJ, Park SW, Seung KB, Choi KB, Shishkov M, Schlendorf K, Pomerantsev E, Houser SL, Aretz HT and Tearney GJ. Visualization of coronary atherosclerotic plaques in patients using optical coherence tomography: comparison with intravascular ultrasound. J Am Coll Cardiol. 2002; 39:604-9. | Article | PubMed

14. Kubo $T$, Imanishi T, Takarada $S$, Kuroi $A$, Ueno $S$, Yamano T, Tanimoto $T$, Matsuo Y, Masho T, Kitabata H, Tsuda K, Tomobuchi Y and Akasaka T. Assessment of culprit lesion morphology in acute myocardial infarction: ability of optical coherence tomography compared with intravascular ultrasound and coronary angioscopy. J Am Coll Cardiol. 2007; 50:933-9. | Article | PubMed

15. Fayad ZA, Fuster V, Nikolaou K and Becker C. Computed tomography and magnetic resonance imaging for noninvasive coronary angiography and plaque imaging: current and potential future concepts. Circulation. 2002; 106:2026-34. | Article | PubMed

16. Briley-Saebo KC, Mulder WJ, Mani V, Hyafil F, Amirbekian V, Aguinaldo $J G$, Fisher EA and Fayad ZA. Magnetic resonance imaging of vulnerable atherosclerotic plaques: current imaging strategies and molecular imaging probes. J Magn Reson Imaging. 2007; 26:460-79. | Article | PubMed

17. P. Tracqui and J. Ohayon. Rotational microrheology of multiplayered finite elastic media. J. Appl. Phys. 2007; 102:1-6. | Article

18. I Ohayon, G. Finet, F. Treyve, G. Rioufol and O. dubreuil. A threedimensional finite element analysis of stress distribution in a coronary atherosclerotic plaque: In-vivo prediction of plaque rupture location. Biomechanics applied to computer assisted surgery. 2005; 225-241. | Pdf

19. Baldewsing RA, Schaar JA, Mastik F and van der Steen AF. Local elasticity imaging of vulnerable atherosclerotic coronary plaques. Adv Cardiol. 2007; 44:35-61. | Article | PubMed

20. Beattie $D, X u C$, Vito R, Glagov S and Whang MC. Mechanical analysis of heterogeneous, atherosclerotic human aorta. J Biomech Eng. 1998; 120:602-7. | Article | PubMed

21. Baldewsing RA, Mastik F, Schaar JA, Serruys PW and van der Steen AF. Young's modulus reconstruction of vulnerable atherosclerotic plaque components using deformable curves. Ultrasound Med Biol. 2006; 32:201-10. | Article | PubMed

22. H. Mohammadi and K. Mequanint. Effect of Stress Intensity Factor in Evaluation of Instability of Atherosclerotic Plaque. Journal of Mechanics in Medicine and Biology. 2014; 14:1450072. | Article

23. Ohayon J, Finet G, Gharib AM, Herzka DA, Tracqui P, Heroux J, Rioufol G, Kotys MS, Elagha A and Pettigrew RI. Necrotic core thickness and positive arterial remodeling index: emergent biomechanical factors for evaluating the risk of plaque rupture. Am J Physiol Heart Circ Physiol. 2008; 295:H717-27. | Article | PubMed Abstract | PubMed Full Text

24. Heiland VM, Forsell C, Roy J, Hedin U and Gasser TC. Identification of carotid plaque tissue properties using an experimental-numerical approach. J Mech Behav Biomed Mater. 2013; 27:226-38. | Article | PubMed 
Mohammadi et al. Cardiovascular System 2015,

http://www.hoajonline.com/journals/pdf/2052-4358-3-3.pdf

doi: $10.7243 / 2052-4358-3-3$

25. Raghu R, Vignon-Clementel IE, Figueroa CA and Taylor CA. Comparative study of viscoelastic arterial wall models in nonlinear one-dimensional finite element simulations of blood flow. J Biomech Eng. 2011;

133:081003. | Article | PubMed

26. Muller O, Pyxaras SA, Trana C, Mangiacapra F, Barbato E, Wijns W, Taylor $\mathrm{CA}$ and De Bruyne B. Pressure-diameter relationship in human coronary arteries. Circ Cardiovasc Interv. 2012; 5:791-6. | Article I PubMed

\section{Citation:}

Zareh M, Fradet G, Naser G and Mohammadi H. Are two-dimensional images sufficient to assess the atherosclerotic plaque vulnerability: a viscoelastic and anisotropic finite element model.

Cardio Vasc Syst. 2015; 3:3.

http://dx.doi.org/10.7243/2052-4358-3-3 